CUM LAUDE

Revista del Doctorado en Derecho

Facultad de Derecho y Ciencias Sociales y Políticas UNNE

$\mathrm{N}^{\circ} 4$ - Abril 2017

Corrientes - Argentina

ISSN: 2422-6408

info@revistacumlaude.com

FECHA DE RECEPCIÓN: 09/03/2016

FECHA DE ACEPTACIÓN: 31/08/2016

\title{
¿Por QUÉ la PaRTiciPación CIUdAdana?
}

\author{
VÍctor ENRIQUe MonTEnEgro StOIANOFF \\ Facultad de Derecho y Ciencias Sociales y Políticas \\ UNIVERSIDAD NACIONAL DEL NORDESTE
}

\section{RESUMEN}

Intentamos en este artículo hacer un breve análisis crítico, de algunas teorías que intentaron explicar de alguna forma lo que es la democracia como participación ciudadana, los primeros autores que tomamos son más positivos a la hora de explicar la resolución del conflicto participativo, buscan de alguna forma, encontrar el interés general, pero por el contrario, tomamos también en los últimos autores, teorías que nos evidencian la imposibilidad de lograr un interés general a través de la participación ciudadana. Entonces el autor de este artículo se pregunta, ¿por qué la participación ciudadana? 


\title{
¿POR QUÉ La PARTICIPACIÓn CIUDADANa?
}

\section{Palabras Clave}

Democracia - disenso - consenso - interés general -interés particular

\begin{abstract}
We try in this article to make a brief critical analysis of some theories that tried to explain somehow what is democracy and citizen participation, the first authors we are more positive in explaining the resolution of participatory conflict, seeking somehow, to find the general interest, but on the other hand, we also take in recent authors, theories that show us the impossibility of achieving a general interest through citizen participation. Then the author of this article asks himself, why citizen participation?
\end{abstract}

\section{KEY WORDS}

Democracy - dissent - consensus - general interest -private interest

\section{INTRODUCCIÓN}

Intentamos en este artículo hacer un breve análisis crítico de algunas teorías que intentaron explicar de alguna forma lo que es la democracia como participación ciudadana, los primeros autores que tomamos son más positivos a la hora de explicar la resolución del conflicto participativo, buscan de alguna forma, encontrar el interés general. Autores contemporáneos como Dworkin, Rawls, los preferimos en nuestra selección ya que son algunos de los más citados en la actualidad por la doctrina jurídica y la filosofía jurídica, otros autores como Quiroga Lavié de la doctrina nacional, lo tomamos para hacer una bajada al territorio legal constitucional argentino. Pero, por el contrario, tomamos también en los últimos autores, teorías que nos evidencian la 
imposibilidad de lograr un interés general a través de la participación ciudadana, y es cuando tomamos autores que no son contemporáneos entre ellos, ejemplo, entre Ranciere e Von Ihering, donde el esfuerzo para comprender el hilo argumental puede ser de mayor dificultad. Entonces el autor de este artículo se pregunta, ¿por qué la participación ciudadana?

\section{DWORKIN, CONSTITUCIONALISMO Y PARTICIPACIÓN CIUDADANA}

Para dar un tratamiento legal al tema en cuestión, según como veremos más adelante, nos focalizamos en los objetivos legales, como finalidad deseada por la sociedad, por lo cual es indispensable no omitir al jurista Dworkin (2003), quien nos orienta en este nuevo paradigma de la participación ciudadana. El libro se titula Liberalismo, Constitución y Democracia, consta de dos trabajos, uno llamado "Liberalismo" y el segundo "Igualdad, democracia y constitución: Nosotros, el pueblo, en los estrados", lo que nos interesa a nosotros que resulta obvio es este segundo escrito. Dworkin (2003) comienza planteándose el problema de la democracia en sí misma, se pregunta si existe algún tipo de método interpretativo al léxico empleado expresamente por la Constitución, y si los mismos enunciados constitucionales son democráticos o antidemocráticos en la praxis, en la revisión judicial, y como estructuras de gobierno. Luego de exponer algunas de las teorías más atrayentes y criticar sus deficiencias, trata de dar una respuesta.

El problema de la democracia es genuino e insoluble. Creo que la cuestión fue mal interpretada y exagerada porque los constitucionalistas se concentraron demasiado en lo que dicta y hace la Constitución, y en cómo debería ser interpretada, no lo suficiente en aquello que la democracia realmente es. (Dworkin, 2003, p. 49) 


\section{¿POR QUÉ La PARTICIPACIÓn CIUDADANa?}

En este párrafo el autor intenta definir lo que se entenderá por democracia, lo que realmente es la democracia, expresando que es una "acción colectiva" y esta última puede ser vista como una "acción colectiva estadística" o como una "acción colectiva comunitaria", la primera que no viene al tema consiste en mediciones cuantitativas, por ejemplo, cuando queremos fundamentar la democracia en la mayoría alcanzada para un quórum. La acción colectiva comunitaria en cambio es cualitativa y fundamenta la democracia en el pueblo mismo, por ejemplo, la participación del pueblo en las decisiones que den quórum. Por último, subdivide a esta última en dos clases, la acción comunitaria colectiva integrada que remarca la importancia de lo individual y la acción colectiva comunitaria monolítica que niega tal importancia. Lo que a nosotros nos interesa es la primera, ya que busca la participación de la sociedad en su conjunto, accionando colectivamente en vísperas de soluciones colectivas, pero respetando siempre los derechos propios individuales (Ej. derechos humanos).

Este autor continúa argumentando una interpretación democrática comunitaria y expresa:

En una democracia genuina, el pueblo gobierna no en forma estadística sino comunitaria. Considera a su nación como una unidad colectiva de responsabilidad, lo cual significa que, en tanto ciudadanos, comparten las responsabilidades que derivan de todo aquello que su gobierno hace en actuar oficial. (Dworkin, 2003, pp. 62-63)

Esto no es otra cosa que un contraargumento contra la interpretación literal de la constitución como estadística, lo titula "Democracia como integración" a este nuevo paradigma democracia y participación. Dworkin (2003) como para cerrar la idea se arriesga a proponer tres principios rectores de esta nueva interpretación.

A- El principio de participación: 
En una democracia entendida como gobierno comunitario de iguales, a cada persona debe ofrecérsele un rol que le permita marcar una diferencia en el carácter de las decisiones políticas, y la fuerza de ese rol - la magnitud de la diferencia que pueda marcar - no debe estar estructuralmente fijada, o limitada por suposiciones acerca de su valía, talento o habilidades. (p. 64)

Se entiende por participación en temas políticos, fuerza, peso político en la interacción de cualquier ciudadano. Esto explica el autor cuando analiza previamente la igualdad en términos estadísticos, o la llamada igual entre iguales, que en palabras de Dworkin (2003) es falsa, por lo menos si queremos hablar de democracia genuina.

B- El principio de interés:

Es el interés en común de toda la ciudadanía en temas políticos, se relaciona con la responsabilidad colectiva, aceptación de toda la ciudadanía en tomar partido por los errores y aciertos, y no meramente juicios, críticas personificadas. "En una democracia comunitariamente entendida, las decisiones colectivas deben reflejar igual consideración por los intereses de todos sus miembros" (Dworkin, 2003, p. 66). "La cuestión acerca de cómo la comunidad trata a sus miembros es parte de lo que determina si éstos pertenecen, y, por lo tanto, si las decisiones políticas son tomadas por un agente colectivo que los incluya" (p. 67). "El principio de interés distingue la democracia comunitaria de la meramente estadística" (p. 68).

Se remarca el léxico inclusión, inclusión política, como venimos adelantando. Por último, tenemos:

C- El principio de independencia:

Este principio rescata al pensamiento comunitario del totalitario, ya que es sabido que todo el siglo XX se vio afectado por esta confusión, por lo tanto, podemos pensar en una comunidad participativa sin imposición de ideas supremas, fascistas, 


\section{¿POR QUÉ La PARTICIPACIÓn CIUDADANa?}

teleológicas, etc. Rescatando la independencia de cada ser humano ciudadano, sus pensamientos, ideologías y consensuando en la interacción con los demás. De aquí que también se relaciona y es parte del tema la tolerancia, el consenso y disenso de una democracia comunitaria. "Una tiranía mayoritaria, en la cual a las minorías les es sistemáticamente negada la justa participación, podría, sin embrago, ser una perfecta democracia estadística" (Dworkin, 2003, p. 68).

Cuando insistimos en que una genuina democracia debe tratar a todos con igual consideración, damos un paso decisivo hacia una forma de acción colectiva más profunda, en la cual la formula "nosotros, el pueblo" se entiende que no incluye a la mayoría sino a todos, actuando comunitariamente. (Dworkin, 2003, p. 68)

Es determinante el léxico empleado de igualdad relacionado no solo con la mayoría, sino con todos. No se trata de escuchar la mayoría, o de imponer ideas, sino de profundizar la acción colectiva.

Proseguimos nuestro análisis de la participación ciudadana, siguiendo ahora a otro autor, netamente nacional, profesor de la UBA e investigador del CONICET, quien propone justificar la democracia, se trata del Dr. Ricardo Maliandi. En el libro "En torno a la democracia" expresa:

Al margen de que se acepte o no la discutida concepción "Contractualista" del Estado, creo que, en principio, es posible admitir que toda forma de gobierno, o de constitución estatal, representa una manera de resolver - de impedir- conflictos sociales. La democracia consistiría, entonces, en el tratamiento de tales conflictos teniendo en cuenta los intereses de todos los involucrados y permitiendo, y garantizando, la libre participación de todos los involucrados. (Maliandi, 1990, p. 50)

De lo que nos habla no es otra cosa que la idea contractual de la fundamentación del Estado, con su basamento en las teorías de Rousseau, Hobbes, Locke, teorías 
contractualistas, pero lo que nos interesa a nosotros es la última parte, donde bien dice que aceptando o no estas ideas, no se puede negar a una democracia su carácter conflictual y la resolución de los mismos por medios consensuales y de participación. El autor así nos expresa a renglón seguido que es necesario tres rasgos fundamentales para fundamentar toda democracia: "1- sufragio universal (participación de todos); 2defensa efectiva de los derechos humanos; y 3- conciencia de conflictividad" (Maliandi, 1990, p. 50).

Los dos primeros pueden tener su basamento jurídico, lo podemos encontrar en la constitución, pero el tercero es un rasgo ético social, que guía a los dos primeros, se trata de un principio rector para una interpretación constitucional real. "El modelo democrático basa el orden en la participación de todos, porque considera que ese orden es más racional que el emanado del arbitrio de un ocasional "iluminado" (Maliandi, 1990, p. 54).

Esto viene a colación del rasgo democrático participativo y no meramente representativo. En este punto podemos ya citar el anteproyecto de reforma constitucional por Quiroga Lavié (1992), para la República Argentina en el año 1994. Este autor comienza describiendo los distintos proyectos a lo largo de la historia argentina, con respecto al artículo $1 \mathrm{CN}$ y a la temática democrática, desde 1853 con el proyecto de Alberdi hasta nuestros días en la última reforma. Cita este autor a modo de fundamento la propuesta de los diputados Unamuno y Maya en 1984 para una reforma constitucional:

El establecimiento del estado social de derecho - o estado de justicia-, basado en la consolidación de un orden jurídico democrático que asegure la plena participación de los gobernados, dentro de un marco de solidaridad, de ejercicio irrestricto de las libertades públicas y de justa distribución del ingreso nacional. (Quiroga Lavié, 1992, p. 43) 


\section{¿POR QUÉ La PARTICIPACIÓn CIUDADANa?}

Son pautas para la reforma, en lo que nos interesa se puede apreciar la expresión de un orden democrático que "asegure" la plena participación de los ciudadanos. Este autor finaliza el capítulo en lo que refiere a la temática, expresando cómo debería quedar redactado el artículo primero de la $\mathrm{CN}$.

Artículo 1- La Nación Argentina se organiza como estados sociales de derecho, de plena justicia y participación, que se realiza en una sociedad pluralista y que adopta para su gobierno la forma representativa, republicana y federal, según lo establece la presente constitución. (Quiroga Lavié, 1992, p. 45)

Lo que nos interesa es el término "participación" agregado, pero bien antes se hizo indispensable pronunciarse por un estado social de derecho.

\section{PARTICIPACIÓN CIUdAdANA EN RELACIÓN CON LA DESOBEDIENCIA CIVIL DE RAWLS}

Antes que nada es importante aclarar que no tratamos la posición original de Rawls por creer de imposible realización, teóricamente es fascinante replantearse el velo de la ignorancia antes de cada acción participativa en la sociedad, pero ello no ocurre porque el ser humano no busca el interés general según el velo de la ignorancia, el ser humano para su felicidad no siempre se ve impulsado a buscarlo, sino por el contrario, solo busca deseos de propio interés, que como veremos más adelante desvirtúan todo intento de finalidad objetiva estática para la sociedad. Por ello sí creemos más importante tratar el concepto de desobediencia civil que fue tratado por el mismo autor en la misma obra de la teoría de la justicia, como una forma de desahogar la crítica antes expuesta.

Rawls (2012) para precisar el concepto de desobediencia civil la distingue del concepto "rechazo de conciencia", la desobediencia civil sería "un acto público, no 
violento, consciente y político, contrario a la ley, cometido habitualmente con el propósito de ocasionar un cambio en la ley o en los programas del gobierno" (p. 332).

Rawls (2012), cree encontrar en este concepto la solución a la disconformidad de los diversos intereses, sin perder el control del estado, lo que busca es un estado ordenado según los parámetros determinados con anticipación y entendidos como "correctos", pero él mismo reconoce que su solución teórica solo funcionaría "En un estado democrático más o menos justo para aquellos ciudadanos que reconocen y aceptan la legitimidad de la constitución” (p. 331).

El problema de la actualidad, es que en algunas democracias modernas (el Estado Argentino por ejemplo en lo contemporáneo) existe una radical disconformidad hacia las instituciones fundamentales, las cuales no pueden siempre cambiar por mecanismos no violentos (todo tipo de mecanismos al límite o al margen de lo legal), ya que existen generaciones de intereses que la sostienen a cualquier precio - utilizando muchas veces un estado de excepción permanente, ejemplo los decretos de necesidad y urgencia permanentes por parte del poder ejecutivo o medidas cautelares por parte de empresas privadas monopólicas que detentan un poder real-, o el mismo sistema jurídico no lo permite por medios legales, por lo cual nos vemos atrapados por el concepto por defecto de Rawls (2012) "rechazo de conciencia” el cual queda fuera de su teoría:

El militante, por ejemplo, se opone mucho más profundamente al sistema político vigente, no lo acepta como casi justo o razonable, o bien cree que difiere ampliamente de sus principios declarados o que persigue una errónea concepción de la justicia. (p. 335)

El autor que seguimos intenta darnos una idea ejemplificativa, luego nos define; "El rechazo de conciencia no se basa necesariamente en principios políticos, puede 


\section{¿POR QUÉ La PARTICIPACIÓn CIUDADANa?}

fundarse en principios religiosos o de otra índole, en desacuerdo con el orden constitucional” (Rawls, 2012, p. 336).

La pregunta problema queda determinada por la actualidad real donde vivimos, ¿cómo lidiamos con el rechazo de conciencia? ¿Estamos lejos de ser una sociedad justa, solo porque tenemos rechazo de conciencia? $\mathrm{O}$ en todo caso, ¿estamos siendo justos en la sociedad al admitir todo tipo de generación de rechazo de conciencia?

\section{EL DESACUERDO POLÍTICO EN JACQUES RANCIÈRE}

En este punto seguiremos en nuestra argumentación a Rancière (1996), quien nos habla sobre la razón del desacuerdo, y ¿por qué optamos por este autor? La razón próxima está al comienzo de su obra, cuando utiliza los términos "ser parte" o "no ser parte", y ésto es importante determinar, ya que en una discusión sobre cuáles deberían ser los mecanismos adecuados para canalizar una demanda de rechazo de conciencia, habría que preguntarse si las mismas personas que lo pugnan ya "no serían parte" del sistema, en tal caso en palabras de Rancière (1996) no tendrían voz:

Puesto que el problema no es entenderse entre gente que habla, en sentido propio o figurado, lenguas diferentes, como tampoco remediar fallos del lenguaje mediante la invención de lenguajes nuevos. Es saber si los sujetos que se hacen contar en la interlocución son o no son, si hablan o si hacen ruido. (p. 69)

Esta argumentación nos hace ver que por más que en una sociedad se escuchen, procesen $\mathrm{y}$ acepten contenidos que rechazan conciencia estructurada, no significa necesariamente que ocurra un caos social apocalíptico, y es más, podríamos decir que estamos siendo más justos políticamente: "Hay política si la comunidad de la capacidad argumentativa y la capacidad metafórica es susceptible de suceder en cualquier momento y por obra de quienquiera" (Rancière, 1996, p. 81). 
Creo que estas palabras del autor citado son suficientes para concluir en lo que hace a la razón del desacuerdo político, entonces nos preguntamos, si el desacuerdo es necesario y de imposible radicación en un estado democrático, ¿cómo deberíamos actuar en sociedad? ¿cómo deberíamos pensar el derecho?

\section{LA PARTICIPACIÓN CIUDADANA Y LA LUCHA POR EL DERECHO EN VON IHERING}

Deberíamos pensar el derecho como una lucha, una lucha por la defensa de nuestros intereses. Qué tiene que ver la lucha por el derecho de Von Ihering por sobre lo que hoy en día conocemos como participación ciudadana, porque hoy en día todavía discutimos sobre si la democracia debe ser participativa, cuando el autor citado ya nos decía hace más de cien años, en pleno siglo moderno, que el derecho es una lucha, posiblemente los autores contemporáneos lo contextualizan dentro de una realidad que no se condice con la actualidad, pero la claridad en la argumentación es suficiente para darle todo el crédito que se merece.

El autor trata en su obra, primero lo que es la lucha por el derecho en general, luego trata el interés en la lucha por el derecho, y finalmente concluye subdividiendo en dos la lucha por el derecho: "en la esfera individual" y "en la esfera social".

Von Ihering (1974) nos dice, en el comienzo de su exposición, "la paz es el término del Derecho, la lucha es el medio para alcanzarlo" (p. 9). "El Derecho es el trabajo sin descanso, y no solamente el trabajo de los poderes públicos, sino también el de todo el pueblo" (p. 10). “...el nacimiento del Derecho es siempre como el del hombre, un doloroso y difícil alumbramiento" (p. 19).

Parecería querer decir que, si el pueblo no acciona, nadie accionaría por el mismo, y que todas las conquistas reconocidas por el derecho al hombre, fueron fruto de 


\section{¿POR QUÉ La PARTICIPACIÓN CIUDADANa?}

una larga lucha por los mismos. Esto no es otra cosa que el reconocimiento del interés social o individual por parte del derecho. El autor nos dice que, si una persona persigue la paz y no defiende su derecho en algún caso esporádico, no habría mayor problema, pero si estaríamos en problema si esto se acrecienta en la sociedad, si sucede frecuentemente que las personas no luchen por su derecho, entonces nos dice: “... se destruiría el derecho mismo, porque predica la fuga ante la injusticia, mientras que el derecho no existe sino luchando contra esta" (Von Ihering, 1974, p. 25).

Desde el punto de vista individual la lucha por el derecho siguiendo al autor, tiene dos condiciones, primero el dolor:

La patología del sentimiento legal es para el legista y para el filósofo del Derecho, o debería ser, porque sería inexacto afirmar que esto es así, lo que la patología del cuerpo humano es para los médicos, y revela indudablemente el secreto de todo el Derecho. (Von Ihering, 1974, p. 41)

Segundo, el carácter: “...la fuerza de acción, es una pura cuestión de carácter” (Von Ihering, 1974, p. 43).

Desde el punto de vista social el autor acentúa la importancia que tiene el hombre que defiende el derecho privado, nos dice: "Los que defienden el derecho privado son los únicos que pueden luchar por el derecho público y por el derecho de gentes" (Von Ihering, 1974, p. 62). "El hombre... combatiendo por su derecho, lo defiende en su totalidad; pero sabe además, que defendiendo el derecho en general, lucha por su derecho personal"' (p 64).

Esto es muy interesante, a esta conclusión que llega el autor es de suma importancia para nuestra hipótesis, en este trabajo sobre el por qué de la participación ciudadana, y su relación con el interés en lo privado. "El medio más vigoroso para 
proteger la nación contra una invasión extranjera es la fuerza moral unida al sentimiento del Derecho despertado en el pueblo" (Von Ihering, 1974, p. 65).

\section{CONCLUSIÓN: ¿POR QUÉ LA PARTICIPACIÓN CIUDADANA? EL AUTOR}

La participación ciudadana es una cuestión social, pero directamente influida por una cuestión individual que la hace imperfecta a los ojos subjetivos. Objetivamente los mismos problemas sociales no serían problemas sino elementos que hacen a la realidad de una sociedad en un momento dado. ¿Cómo es esto?

Desde el punto de vista individual no es necesario participar en política si la persona que vive en sociedad tiene un sentido egoísta relativo por lo social, no le afecta a sus principios morales, no le hace sentir mal a sí mismo, o bien sintiéndose mal puede conseguir una felicidad relativa, puede continuar con su vida normalmente, o hasta sintiéndose absolutamente mal e infeliz desea de todas formas soportar la misma ya sea por ignorancia, ideología, o desconocimiento de la felicidad, este último caso no existiría, ya que la infelicidad sería lo normal y lo único conocido. El problema de todas formas estaría dado por la finalidad de la propia vida, si la finalidad de tu vida no estaría dada necesariamente por la necesidad de participar en política, entonces no hace falta que una persona participe políticamente. Ahora bien, si la persona se ve molesta por las actitudes políticas de la sociedad puede tomar parte para modificar su molestia o aguantar, o dejar pasar la misma molestia. En definitiva, el problema desde el punto de vista individual siempre sería relativo a los objetivos y sentimientos de cada persona, cuestión que no nos interesa, porque consideramos que la participación ciudadana es una cuestión social y no individual, como lo veremos seguidamente. 


\section{¿POR QUÉ La PARTICIPACIÓn CIUDADANa?}

Desde el punto de vista social, decimos que tenemos que participar en política no sólo porque: 1- las personas nacen y mueren en sociedad; 2- sino también porque creemos que parte de los ser humanos, no sólo son malos en estado de naturaleza como creía Hobbes (2010), sino también son malos en estado social, malo en el sentido social, malo socialmente, contrario a los intereses sociales, los intereses sociales estarían dados por lo que la sociedad considera la forma correctamente de actuar y ser, forma que si bien se plasma en la cultura arrastrada por la historia social, solo lo analizaremos desde el punto de vista legal, creemos que el análisis legal nos dice mucho con respecto a la finalidad buscada por la sociedad, pero vemos que es la misma sociedad, la que busca no cumplir con las mismas normas creadas, sostenidas y buscadas, entonces la sociedad busca otra cosa o busca esa misma finalidad legal pero solo cuando le conviene a sus intereses, no creemos que lo primero pueda sostenerse porque no puede existir tampoco una contradicción absoluta, sino más bien creemos en lo segundo, existe una contradicción relativa que funciona casi mecánicamente según el interés particular de la persona que tiende a tomar una determinación en un momento dado en su vida, esa determinación obviamente es de cuestión individual. Por lo tanto, debemos participar en política solo por un interés individual, que puede ser de objetivo particular o grupal, pero que en su lucha mutua contra otros intereses particulares nos va a reflejar en la sociedad la realidad dinámica de la lucha de los intereses. La participación así, es voluntaria, pero nos enseña que si no participamos nos quedamos fuera de la pugna por hacer cumplir, mantener o conseguir nuestro interés particular o grupal. Los objetivos solidarios solo existen porque hay un porcentaje en la sociedad que desea intereses sociales reflejados en otro u otros sectores de la sociedad, y desea actualmente, de diversas maneras y métodos, ayudar a personas que no pueden, -por falta de poder o 
cualquier otra índole- hacer cumplir sus objetivos particulares y muchas veces no desean ningún otro objetivo solidario que el determinado -ya sea por una cuestión de cualquier índole, de imposibilidad física o económica-. Pero en definitiva la participación siempre se trata de una lucha por el interés deseado, particular o grupal, pero jamás una lucha por un interés general, ya que si es general no habría con quien luchar.

\section{REFERENCIAS BIBLIOGRÁFICAS}

Dworkin, R. (2003). Liberalismo, Constitución y Democracia. Buenos Aires: La isla de la luna.

Hobbes, T. (2010). Leviatan. Buenos Aires: Editorial Libertador.

Maliandi, R. (1990). Justificación de la Democracia. En R. Vigo (Coord.), En torno a la Democracia. Santa Fe: Rubinzal - Culzoni.

Quiroga Lavié, H. (1992). Propuesta para Reforma de la Constitución Argentina (tomo 1). San Luis: Editorial Universitaria.

Rawls, J. (2012). Teoría de la Justicia. D. F. México: Fondo de Cultura Económica.

Rancière, J. (1996). El Desacuerdo Politica y Filosofía. Buenos Aires: Ediciones Nueva Visión.

Von Ihering, R. (1974). La Lucha por el Derecho. Buenos Aires: Editorial Heliasta.

\section{Curriculum Vitae}

El autor es Abogado egresado de la UNNE, alumno regular del Doctorado en Derecho de la Facultad de Derecho de la UNNE, Especialista en Administración Financiera y Control de las Organizaciones Públicas de la UCP, Profesor Adscripto de 
la Cátedras Filosofía del Derecho y Derecho Administrativo, ambas de la UCP y Profesor invitado disertante en la materia Historia del Pensamiento de la Carrera de Comercio Exterior de la UCP.

Correo electrónico: victorenrique_ms@hotmail.com 